\title{
Herpes simplex virus hepatitis 4 years after liver transplantation
}

\author{
Karl-Dimiter Bissig ${ }^{1}$, Arthur Zimmermann ${ }^{2}$, Dirke Bernasch ${ }^{3}$, Hansjakob Furrer ${ }^{3}$, \\ and Jean-François Dufour ${ }^{4}$ \\ ${ }^{1}$ Division of Internal Medicine, Inselspital, Bern, Switzerland \\ ${ }^{2}$ Institute of Pathology, Inselspital, Bern, Switzerland \\ ${ }^{3}$ Institute of Infectious Diseases, Inselspital, Bern, Switzerland \\ ${ }^{4}$ Department of Clinical Pharmacology, University of Bern, Murtenstrasse 35, 3010 Bern, Switzerland
}

If not promptly recognized and treated, herpes simplex virus (HSV) hepatitis is associated with a high mortality. A patient transplanted for primary sclerosing cholangitis required, 4 years later, a colectomy for a steroid-resistant flare of ulcerative colitis. He subsequently developed fever, with genital and oral ulcerations. He was hospitalized for diabetic decompensation with massive elevation of serum aminotransferases. Examination revealed vesicles on the hands. Liver biopsy showed Cowdry type B inclusions. Therapy with acyclovir was immediately initiated and the patient recovered. This case illustrates the diagnostic importance of mucocutaneous lesions in the assessment of complications after liver transplantation.

Key words: herpes simplex, hepatitis, orthotopic liver transplantation, immunosuppression

\section{Introduction}

Herpes simplex virus (HSV) is a ubiquitous virus which usually infects mucocutaneous epithelial and neuronal cells. Rarely, HSV disseminates to infect other cell types, such as hepatocytes, leading to severe parenchymal damage. It is crucial to recognize and treat HSV hepatitis without delay to improve its dismal outcome. We discuss a patient hospitalized 4 years after liver transplantation for rapidly developing severe hepatitis. The presence of vesicles on the hands, as well as genital and oral ulcerations, raised the suspicion of HSV infection. A liver biopsy confirmed the dissemination of the infection. The patient recovered with antiviral therapy.

Received: August 1, 2002 / Accepted: November 22, 2002 Reprint requests to: J.-F. Dufour
Careful examination of the tegument may provide important diagnostic clues in patients developing complications after liver transplantation.

\section{Case report}

Our patient was diagnosed with Crohn's disease at the age of 22 and underwent orthotopic liver transplantation 14 years later for endstage primary sclerosing cholangitits. The immediate postoperative course was uneventful and the patient was discharged on the ninth postoperative day. Two months after transplantation, steroids had to be reintroduced for histologically proven rejection, and cyclosporin was replaced by tacrolimus.

Four years after the transplantation, the patient suffered from a severe exacerbation of his inflammatory bowel disease. This flare did not respond to steroids, and the patient underwent a subtotal colectomy. He recovered quickly from surgery. One month later, he declined a liver biopsy, which was indicated for a moderate elevation of serum aminotransferase levels. Prednisone therapy for acute rejection was empirically started ( $600 \mathrm{mg}$ for 3 days, then $40 \mathrm{mg} /$ day) in addition to his immunosuppressive regimen (tacrolimus and azathioprine). The liver test results normalized. Then, he consulted his physician for ulcerated phimosis. Doxycycline was prescribed, but was without effect. A few days later, the patient developed stomatitis, which was interpreted as oral candidiasis and was treated with fluconazole. One day before hospitalization the patient developed fever and skin lesions on both hands. $\mathrm{He}$ appeared in the emergency room with a $38.5^{\circ} \mathrm{C}$ fever and in a severely diminished nutritional status. He had no pain, but complained of polydipsia and pollakiuria. Both hands had multiple vesicular and pustular lesions. He had several ulcerations on the soft and hard palate, as well as on the tongue. Genital examination revealed 

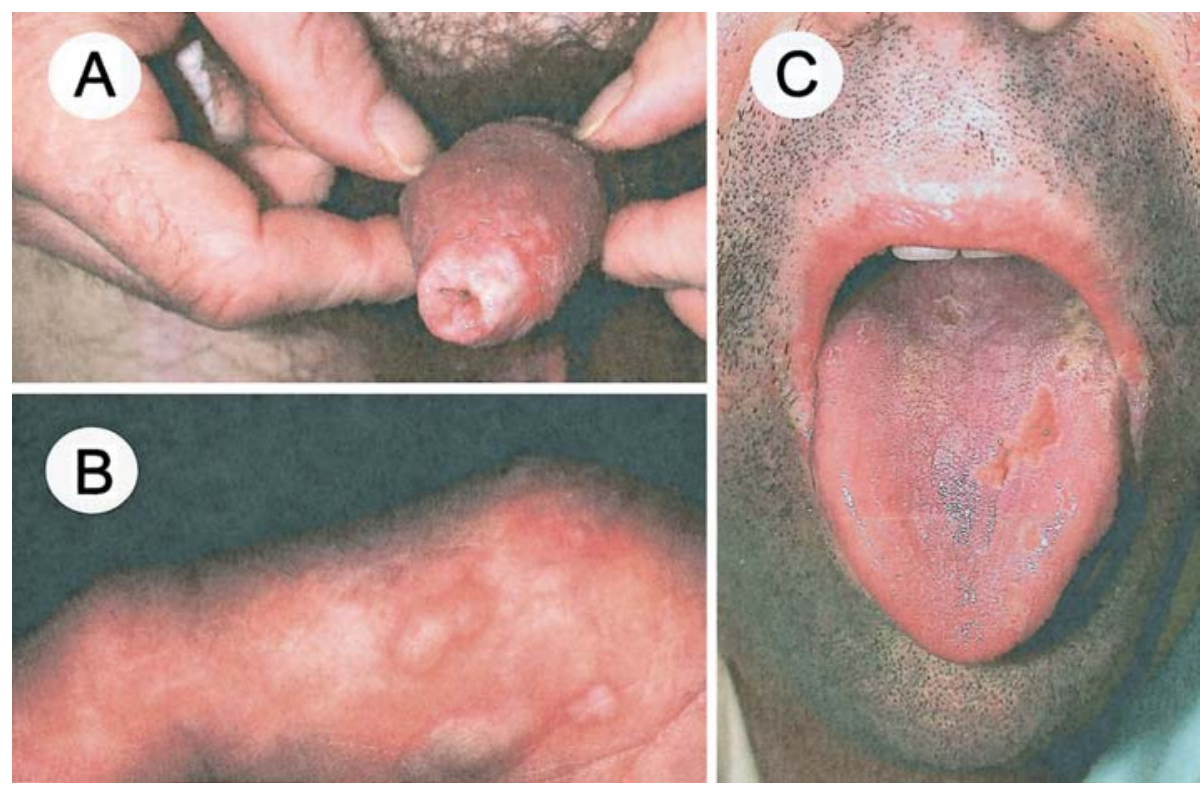

Fig. 1A-C. Mucocutaneous lesions. A Coalescent ulcerations of the foreskin with phimosis. B Numerous vesicular and pustular lesions on the right hand. C Vesicular lesions on the lips, and ulcerations of the tongue coalescent ulcerations on the foreskin, with phimosis (Fig. 1). He was not jaundiced and his liver was not enlarged. Duplex-sonography of the liver was normal. Blood examination revealed a decreased white blood cell count $\left(2500 / \mathrm{mm}^{3}\right)$ and pronounced lymphocytopenia $\left(0.100 / \mathrm{mm}^{3}\right)$. Serum aspartate aminotransferase and alanine aminotransferase levels were 1272 and 843 U/l, respectively (Fig. 2). Serum alkaline phosphatase and $\gamma$-glutamyltransferase levels were $142 \mathrm{U} / 1$ and $413 \mathrm{U} / \mathrm{l}$. Albumin was reduced to $23 \mathrm{~g} / \mathrm{l}$, and the international normalized ratio (INR) was 1.1. Blood glucose concentration was elevated to $55.3 \mathrm{mM}$. Creatinine was $200 \mu \mathrm{M}$ and the serum tacrolimus level was dramatically increased $(80.5 \mathrm{ng} / \mathrm{ml})$. Therapy for diabetic decompensation was started, and a transjugular liver biopsy was performed. Histology revealed several large, rounded, and rather well-delineated foci of coagulative parenchymal necrosis, with disintegration of liver cell plates and accumulation of nuclear debris (Fig. 3A). At the edge of the necrotic zones, several hepatocytes exhibited nuclei with amphophilic viral inclusions lacking a peripheral halo (Cowdry type B inclusions; Fig. 3A). Immunohistochemically, decayed hepatocytes within the necrotic areas and intact cells at their edges were reactive for HSV-1 antigen, with both a nuclear and a cytoplasmic staining pattern (Fig. 3B). There were no histological signs of rejection. Intravenous therapy with acyclovir $(10 \mathrm{mg} / \mathrm{kg}$ body weight $/ 12 \mathrm{~h})$ was immediately started. Cultures from smears of mouth and foreskin were positive for HSV type 1 virus. Hepatitis A, B, and $\mathrm{C}$, as well as Epstein-Barr virus and cytomegalovirus serologies were negative. Complement fixation test for HSV was positive; the same test had been negative

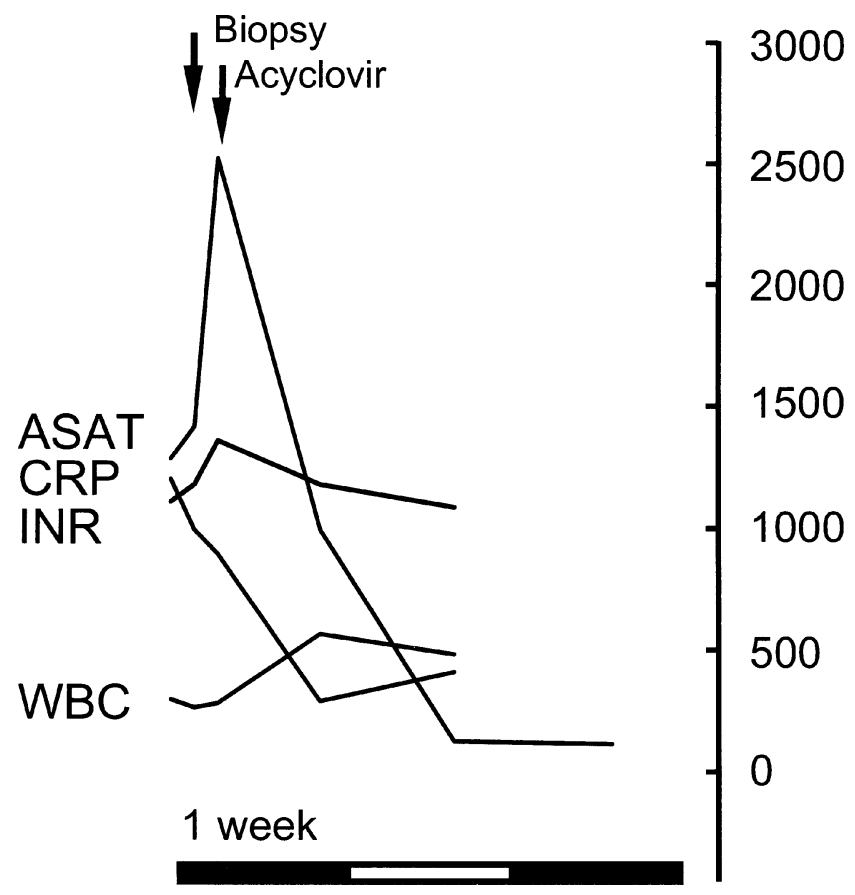

Fig. 2. Synopsis of selected laboratory values during hospitalization. Values on the y-axis show aspartate aminotransferase $(A S A T)$ and alanine aminotransferase $(A L A T)$, in U/l, Creactive protein $(C R P)$, in $\mathrm{mg} / \mathrm{l}$, multiplied by a factor of 10 . The international normalized ratio $(I N R)$ is multiplied by a factor of 1000 and the white blood cell count $(W B C)$ is per $\mathrm{mm}^{3}$, divided by a factor of 10 . Arrows indicate the time of biopsy and the initiation of the acyclovir treatment. The $\mathrm{x}$-axis represents the time; each bar is a week 


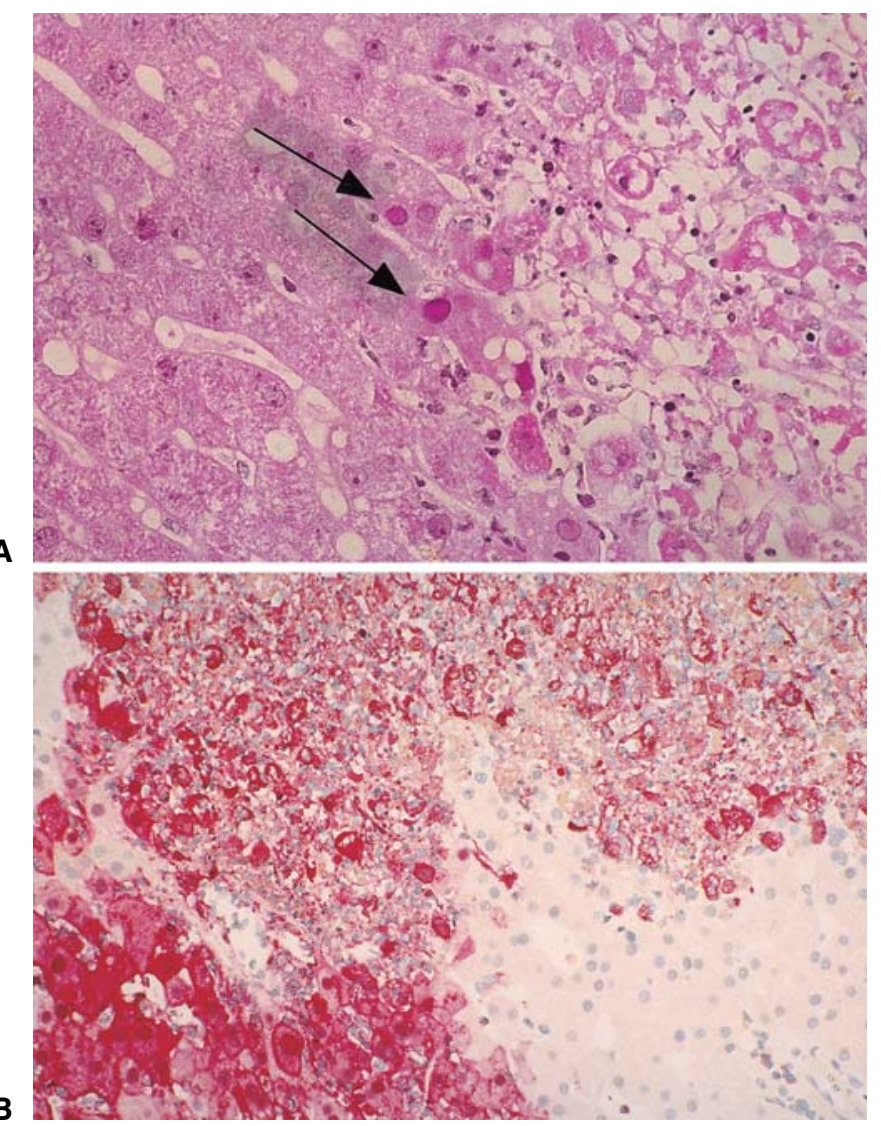

Fig. 3A,B. Histology of liver biopsy specimen. A Fresh coagulative parenchymal necrosis with decay of hepatocytes and much nuclear debris. Note that some hepatocytes (arrows) exhibit nuclei with purple homogeneous nuclear inclusions, corresponding to Cowdry type B inclusions. B Immunostaining for herpes simplex virus (HSV)-1 antigen. Most of the damaged cells within the necrotic zone are reactive (red reaction product), and positivity is even more marked in preserved hepatocytes at the border (including the nuclear inclusion bodies). A H\&E. A,B Original magnification $\times 40$

6 months earlier, supporting the notion of a primary infection. 5 The blood parameters improved (Fig. 2) and, after a few days, the lesions in the mouth and on the hands began to disappear. The patient underwent circumcision under local anesthesia. Two weeks later, the intravenous acyclovir therapy was stopped and he was discharged in good condition 19 days after admission. Five weeks after discharge, insulin therapy could be stopped.

\section{Discussion}

HSV hepatitis is rare in healthy individuals, ${ }^{1-3}$ pregnant women, ${ }^{4-6}$ and neonates. ${ }^{7,8}$ The majority of reports concern immunosuppressed patients, particularly recipients of solid organ transplantation. ${ }^{9-14}$ Kusne and cowork- ers $^{10}$ found that HSV hepatitis mostly occurred early after organ transplantation. Compared to the relatively frequent cytomegalovirus infection, which peaks 30-40 days after transplantation, HSV hepatitis can occur as early as 5 days after liver transplantation, with a median of 18 days. These series had a high mortality; three of four patients with a primary infection, and five of eight patients with a reactivation died. The risk of a fulminant course was three times higher in primary infection $(75 \%)$ than in reactivation $(25 \%)$. Our patient suffered from a primary infection, because HSV serologies and hepatic immunochemistry for HSV-1 antigen were negative on several occasions prior to this infection. Blood analysis of the donor revealed IgG antibodies against HSV type 1. Transmission of HSV through a transplant is possible. ${ }^{11,12}$ However, transmission through the transplanted organ several years after transplantation is unlikely. ${ }^{10}$ This patient was particularly immunosuppressed. He required several prednisone courses, the last one 6 weeks before admission. The development of HSV hepatitis after the use of steroids has been described. ${ }^{15}$ One case report describes a primary infection with HSV-1 in a young patient with inflammatory bowel disease treated with $40 \mathrm{mg}$ prednisone once a day, ${ }^{16}$ a situation comparable to the one reported here, but with a fatal outcome.

Our patient presented not only with severe hepatitis but also with diabetic decompensation. He had received a higher dose of steroids before without requiring insulin, suggesting that this episode was probably not steroid-induced. It may have been due to an infection of the pancreatic $\beta$ cells by the HSV. HSV can occasionally disseminate to the pancreas, but we could not find literature documenting HSV-induced diabetes mellitus. We favor, as an explanation, toxicity of tacrolimus, which reached high concentrations due to the hepatitis. Immunosuppressive drugs such as cyclosporin $\mathrm{A}$ and tacrolimus, which act by inhibiting the phosphatase activity of calcineurin, also impair the regulation of insulin secretion by $\beta$ cells. ${ }^{17}$

Several authors emphasize the importance of the early diagnosis and treatment of herpes simplex hepatitis. ${ }^{18,19}$ Yet early diagnosis can be difficult. A recent literature review showed that only $27 \%$ of patients had oral lesions; $31 \%$ had genital lesions; and only $4 \%$ (two patients) presented with both types of lesions, as in our patient. ${ }^{20} \mathrm{~A}$ liver biopsy should be quickly organized. Acyclovir is the drug of choice for herpes hepatitis, yet doses and duration of therapy have not been established. Intravenous application of $10 \mathrm{mg} / \mathrm{kg}$ per $8 \mathrm{~h}$ in adjustment of renal function is a reasonable adaptation from the dose and duration used for the more common HSV encephalitis. ${ }^{19}$ In fulminant hepatitis, orthotopic liver transplantation ${ }^{1,21}$ or living-donor liver transplantation $^{22}$ can be considered. Fortunately, due to the rapid 
diagnosis and therapy, our patient fully recovered. Typical mucocutaneous lesions in liver-transplanted patients should immediately raise the possibility of HSV hepatitis.

Acknowledgments. This work was supported by "Stiftung für Leberkrankheiten".

\section{References}

1. Chauveau E, Martin J, Saliba F, Nicolas X, Richecoeur M, Klotz F. Fatal fulminating hepatitis due to Herpes simplex virus type 2 in a young immunocompetent female. Med Trop (Mars) 1999;59:58-60.

2. Goodman ZD, Ishak KG, Sesterhenn IA. Herpes simplex hepatitis in apparently immunocompetent adults. Am J Clin Pathol 1986;85:694-9.

3. Rubin MH, Ward DM, Painter CJ. Fulminant hepatic failure caused by genital herpes in a healthy person. JAMA 1985; 253:1299-301.

4. Fink CG, Read SJ, Hopkin J, Peto T, Gould S, Kurtz JB. Acute herpes hepatitis in pregnancy. J Clin Pathol 1993;46:968-71.

5. Glorioso DV, Molloy PJ, Van Thiel DH, Kania RJ. Successful empiric treatment of HSV hepatitis in pregnancy. Case report and review of the literature. Dig Dis Sci 1996;41:1273-5.

6. Stagno S, Whitley RJ. Herpesvirus infections of pregnancy. Part II: herpes simplex virus and varicella-zoster virus infections. N Engl J Med 1985;313:1327-30.

7. Becker WB, Kipps A, McKenzie D. Disseminated herpes simplex virus infection. Its pathogenesis based on virological and pathological studies in 33 cases. Am J Dis Child 1968;115:1-8.

8. Miller DR, Hanshaw JB, O'Leary DS, Hnilicka JV. Fatal disseminated herpes simplex virus infection and hemorrhage in the neonate. Coagulation studies in a case and a review. J Pediatr 1970;76:409-15.

9. Anuras S, Summers R. Fulminant herpes simplex hepatitis in an adult: report of a case in renal transplant recipient. Gastroenterology 1976;70:425-8.

10. Kusne S, Schwartz M, Breinig MK, Dummer JS, Lee RE, Selby R, et al. Herpes simplex virus hepatitis after solid organ transplantation in adults. J Infect Dis 1991;163:1001-7.
11. Dummer JS, Armstrong J, Somers J, Kusne S, Carpenter BJ, Rosenthal JT, et al. Transmission of infection with herpes simplex virus by renal transplantation. J Infect Dis 1987;155:202-6.

12. Koneru B, Tzakis AG, DePuydt LE, Demetris AJ, Armstrong JA, Dummer JS, et al. Transmission of fatal herpes simplex infection through renal transplantation. Transplantation 1988;45:653-

13. Singh N, Dummer JS, Kusne S, Breinig MK, Armstrong JA, Makowka L, et al. Infections with cytomegalovirus and other herpesviruses in 121 liver transplant recipients: transmission by donated organ and the effect of OKT3 antibodies. J Infect Dis 1988;158:124-31.

14. Taylor RJ, Saul SH, Dowling JN, Hakala TR, Peel RL, Ho M. Primary disseminated herpes simplex infection with fulminant hepatitis following renal transplantation. Arch Intern Med 1981;141:1519-21.

15. Keane JT, Malkinson FD, Bryant J, Levin S. Herpesvirus hominis hepatitis and disseminated intravascular coagulation. Occurrence in an adult with pemphigus vulgaris. Arch Intern Med 1976;136:1312-7.

16. Shlien RD, Meyers S, Lee JA, Dische R, Janowitz HD. Fulminant herpes simplex hepatitis in a patient with ulcerative colitis. Gut 1988;29:257-61.

17. Marchetti P, Navalesi R. The metabolic effects of cyclosporin and tacrolimus. J Endocrinol Invest 2000;23:482-90.

18. Chung AB, Fas N. Successful acyclovir treatment of herpes simplex type 2 hepatitis in a patient with systemic lupus erythematosus: a case report and meta analysis. Am J Med Sci 1998:316:404-7.

19. Peters DJ, Greene WH, Ruggiero F, McGarrity TJ. Herpes simplex-induced fulminant hepatitis in adults: a call for empiric therapy. Dig Dis Sci 2000;45:2399-404.

20. Kaufman B, Gandhi SA, Louie E, Rizzi R, Illei P. Herpes simplex virus hepatitis: case report and review. Clin Infect Dis 1997;24:334-8

21. Shanley CJ, Braun DK, Brown K, Turcotte JG, Greenson JK, Beals TF, et al. Fulminant hepatic failure secondary to herpes simplex virus hepatitis. Successful outcome after orthotopic liver transplantation. Transplantation 1995;59:145-9.

22. Uemoto S, Inomata Y, Sakurai T, Egawa H, Fujita S, Kiuchi T, et al. Living donor liver transplantation for fulminant hepatic failure. Transplantation 2000;70:152-7. 